\title{
Interaction of Electric Vehicle and Smart Grid based on Game Theory for Smoothing Peak Load and $\mathrm{CO}_{2}$ Reduction
}

\author{
Zoulikha Bendiabdellah ${ }^{1}$, Hichem Sedjelmaci ${ }^{2}$, Mohamed Attia ${ }^{2}$, \\ Sidi Mohammed Senouci ${ }^{2}$ and Mohammed Feham ${ }^{1}$ \\ ${ }^{1}$ STIC Laboratory, University of Tlemcen, Algeria \\ ${ }^{2}$ Univ. Bourgogne Franche Comté, F58000, 49 Rue Mademoiselle Bourgeois, \\ 58000, Nevers, France \\ E-mail: $\{$ Zoulikh.bendiabdellah; mffeham\}@mail.univ-tlemcen.dz; \\ \{Sid-Ahmed-Hichem.Sedjelmaci; Mohamed.Attia; Sidi-Mohammed.Senouci\} \\ @ u-bourgogne.fr
}

Received 30 March 2016; Accepted 20 May 2016;

Publication 4 August 2016

\begin{abstract}
Vehicle to Grid (V2G) concept concerns the ability to inject the power contained in the batteries of the electric vehicles (EVs) into the smart grid (SG). The present paper deals with this concept in order to flatten the daily load curve with a particular focus on the interaction between EVs and SG. Based on that, a proposed novel model using a Bayesian game approach is built to study this interaction. The model takes into account the major challenges of V2G technology, such as the availability of EV and the battery lifetime. In addition, unlike most of the existing research work, we introduce in our formulation a new factor representing the impact on the environment so as to encourage the usage of renewable sources. This factor has a significant effect on the player's decisions as well as on the simulation results. Finally, with the help of Bayesian Nash Equilibrium (BNE), we study the interaction's probability between players (SG and EV) for three periods of the day (off-peak, mid and peak hours). Simulations are carried out using real data and illustrate the effectiveness and merits of the proposed model in order to answer the raised
\end{abstract}

Journal of Green Engineering, Vol. 6, 51-76.

doi: 10.13052/jge1904-4720.613

(C) 2016 River Publishers. All rights reserved. 
questions: what is the best period of the day chosen by EV to provide power to the electric grid and SG to supply energy from the EV?, and what is the benefit of EV owners, SG and the environment in using V2G technology?

Keywords: Electric vehicle, Game theory, Nash equilibrium, Renewable energy, Smart Grid.

\section{Introduction}

Facing climate changes has become over the years a major priority of governments [1]. Furthermore, the transport sector is considered one of the main factor that causes a deterioration of the environment, ranging from local effects (e.g. noise and $\mathrm{CO}_{2}$ emissions) to a global effect (e.g. climate change). To limit these disastrous problems, a decarbonising road transport appears as an emergency. For this purpose, the electric vehicle (EV) could be an interesting solution [2]; however, electrification transportation will add a significant load (on average 18\%) to the existing power grid causing a negative impact on the grid reliability [3]. On the other hand, EVs are powered by electricity, which represents the major part of original carbon dioxide emissions, where $40 \%$ of global $\mathrm{CO}_{2}$ emissions are related to the production of energy [4]. Hence, it will be useless to electrify the automobile if the electricity that feeds their batteries is not produced with clean energy [5]. Renewable energies are clean energies; they present a major asset over fossil resources (oil, gas, coal) for the production of electricity. In addition, of their green character, the renewable energies are inexhaustible; however, their intermittent and unpredictable production remains a critical challenge associated with the difficulty of integrating them in the power grid $[5,6]$. To make EVs a more attractive solution, we must find a way to develop the integration of clean energy sources and reduce the network overload that would produce a large amount of electric vehicles [7]. A new concept that could meet these objectives based on the use of EVs themselves have appeared with the emergence of recent technological advances in electricity system distribution and load management referred to as "smart grids" (SG), which is the concept of vehicle-to-grid (V2G). Vehicle-to-grid describes a system in which EVs communicate with the power grid to sell demand response services by delivering electricity into the grid [8]. EVs will play a buffer role: accessible, convenient and affordable. The EVs will facilitate the energy storage during their recharge to allow better integration of renewable energy. Moreover the ability to restore this energy from the vehicle to the grid will be 
a windfall for the power system, the EV's owner and the environment $[9,10]$. V2G can be a more economical and effective solution to the grid-demand variations in load balancing by valley filling (i.e. charging at night where demand is low) [11], peak smoothing (i.e. compensating peak load during peak time) [12], stabilizing voltage and frequency, and providing a spinning reserve to meet sudden power demand changes [13]. By using the battery to feed the network, the vehicle owner sells both energy and availability. The V2G therefore has the potential to participate in solving the complex equation of energy storage, while providing a double environmental benefit. In this paper, our aim is to study the interaction between EV and SG in a V2G scheme, in order to flatten the daily load curve with renewable energies. The problem is modeled as a game between EV and SG. Based on Bayesian Nash Equilibrium, we examine the cost-effective, the profit of this interaction by a comparison between the prices that the grid has to pay when it purchases energy from green sources (V2G) and non-green sources. The demand that is the quantity of energy delivered to the grid and the impact on the environment when supplying energy from EV, are also evaluated.

The rest of the paper is organized as follows: Section 2 presents some related works. In Section 3, the theoretical model is presented and detailed. In Section 4, the simulations work is conducted and discussed. Some concluding remarks are provided in Section 5.

\section{Related Work}

The integration of renewable energies in the electricity network system has received a significant attention from researchers over the last decade [14]. With the development of smart grid this research area has been increased and we can cite among the large reported works in the literature: variability of renewable energy sources [15], the integration cost [16], the energy management system [17], the energy storages technologies [18, 19]. Smart grid has brought with it another promising technology for the integration of renewable energies, known as V2G which consists of the return of the energy stored in EVs to the eclectic grid. The idea of V2G was first introduced in [20] and then an increasing research work about V2G was carried out by the scientific community. The concepts surrounding V2G were exposed in [21, 22] and the feasibility of such a system has been demonstrated in [23, 24]. Furthermore, economic justification of $\mathrm{V} 2 \mathrm{G}$ technology (i.e. cost of additional equipment needed for V2G, battery degradation cost, revenue cost for both EV owners and SG) has also been established [21, 25, 26]. V2G brings great challenges 
and opportunities to the power grid [27]. Although, the concept certainly has the potential in improving greatly the development of the power grid and increasing its reliability and its efficiency and also supporting the increasing generation from intermittent renewable energy. There are several challenges that still need to be overcome, such as the relevant battery technology of EVs that attracts the scientific world [28], the need of a reliable two-way communication and the additional issue that the distribution grid has not been designed for bidirectional energy flow. This tends to limit the service capabilities of V2G devices [29]. Methodologies, approaches, and foresights of this emerging technology were discussed and investigated in [10].

In literature, it has been demonstrated that $\mathrm{EV}$ can provide power to serve various markets, spinning reserves, frequency regulation, and smoothing peak power [26]. Spinning reserves and frequency regulation refer to "ancillary services" used by grid operators to maintain the reliable operation of the grid [30]. In ancillary services, EVs may either involve energy delivery to the power grid or simply use the capacity of their batteries without delivering energy to the grid $[23,24]$. Numerous works have been addressed in this area [3, 15, 21, 31-34]. Another service, in which EVs can participate is smoothing peak load, which is the main focus of this paper. Peak load corresponds to a maximum level of electricity demand within a particular period of time (e.g. a specific day or hour of the day). With the extensive adoption of EVs, a large number of EVs charging loads will increase highly peak load $[35,36]$, especially if EVs are charging randomly. The major part of techniques carried out for peak load market can be categorized into two main aspects, the first one uses a controllable smart charging, which charges EVs during off-peak hours when demand is low to avoid peak load [37-41]. In the second one, the proposed techniques use the energy stored in vehicle batteries to compensate the peak load within the concept of V2G [4, 21, 32, 42-44]. In the following, we present some of these works mentioned in these two categories.

For the first alternative, which is the use of a controllable smart charging to avoid peak load, references $[38,39]$ have proposed an evaluation of the impact of this solution in minimizing the additional peak load. They therefore proposed a comparison between a controlled charging scenario and an uncontrolled charging strategy. In [37], the authors developed a mathematical model for the scheduling of plug-in-hybrid-vehicles (PHEV), the charging is based on game theoretic approach that aims to minimize the customers' charging cost in peak hours. With the help of Bayesian game theory, the authors formalized in [40] the interaction between the supply and the consumption of electricity. Afterward, based on Nash equilibrium concept, they proposed an optimal 
strategy that satisfies both the supply and the demand and hence avoided the peak load. In addition, they aimed to integrate the green electricity sources into electricity network in order to charge EVs batteries, with the goal of minimizing the usage of polluting energy sources. The major drawback of these works is that they have the limitation in considering only the vehicle load. In fact, most of them neglect the load of the power grid.

Smoothing peak load within the concept of V2G was addressed in [44] where the authors presented a probabilistic method that models the driving pattern to predict the load demand profile of PHEVs. Based on the obtained load demand, a business model that implements a V2G technology in a residential distribution grid is developed. This model includes three strategies; these are charging, discharging or providing ancillary service to the grid. To find the optimal strategy, a swarm optimization algorithm is proposed. Results showed that the proposed algorithm has the ability to improve the power quality, to reduce the peak load and to provide frequency regulation service. In [42], the authors propose a collision game strategy of PHEV charging and discharging for V2G network. In this game, EVs represent the players and a set of players constitutes a cooperative group, some of these EVs charge and others discharge. In a coalition, the players work cooperatively to enlarge their common benefit and involve the satisfaction of the charging or discharging situations for an optimum cost. According to their simulation results, the authors concluded that the peak-load of power system is significantly reduced. Moreover, the vehicles are satisfied by a low charging cost and a higher stateof-charge (SOC) for most of their trips. However, the major drawback of this work lies in the fact that the battery life time has been disregarded. In [43], a mathematical model to evaluate bi-directional energy transfer from vehicle to grid and grid to vehicle was formulated. The bi-directional energy transfer was discussed at different charge and discharge rates, where the total energy exchanged between the grid and the vehicle was analysed. The authors have found that, due to peak hours transfer of energy between the $\mathrm{EVs}$ and the grid, the transportation cost for the EV integrated into the grid is higher. This is due to the losses associated with the battery during the peakhour energy supply. However, the authors do not consider in their approach the negative impact on the environment resulting from charging/discharging function. In [4], the authors proposed two models to maximize the integration of renewable sources in $\mathrm{V} 2 \mathrm{G}$ system to reduce the $\mathrm{CO}_{2}$ emission and to optimize the environment benefit. The first one is a load-levelling model where EVs are charged through conventional generator using load-levelling optimization and the second is a smart-grid model where EVs are charged 
from renewable sources and discharged to the grid. The authors concluded that the use of EVs alone could not reduce the negative impact of $\mathrm{CO}_{2}$ emission on the environment. Therefore, the success of practical application of vehicle with $\mathrm{V} 2 \mathrm{G}$ capability to achieve emission and cost reductions greatly depends on the maximum utilization of renewable sources. However, the major drawback of this work is that the authors do not consider the type of used vehicle and they have employed a PHEV that contains also on-green combustibles.

From to the vast research we carried, we can make the following findings: (i) to date, few studies have been carried out for the interaction between EV and SG considering the environment benefits, (ii) green environment necessitates the integrating of renewable sources in the power system in order to reduce the high environmental impact of fossil-based energy system, (iii) for a complete study of the interaction between SG and EV in the V2G, we should address EV charging and discharging, and (iv) the use of game theory helps to optimally integrate the EV into a SG.

Motivated by the aforementioned findings, our contributions are as follows:

- We develop a new model of V2G interaction with the key issue related to the integration of renewable sources in smart grid. In order to ensure reduction in $\mathrm{CO}_{2}$ emission and therefore ensure an environmental benefit.

- We formulate our model with a Bayesian game theory.

- The proposed game is in terms of exchange between EV and SG and rests on the idea that the two sides of the system should have a financial gain by participating in V2G. contrary to that, we adopt the time-of-use (TOU), we therefore study the interaction in the three periods of the day (off-peak-time, mid-time and peak-time).

- Our model reposes on a realistic EV battery model which integrates the battery capacity, the battery degradation cost, and the EV availability.

- Finally, we note that, the present work is the complement of the work presented in reference [40].

\section{Vehicle to Grid Interaction: Problem Formulation}

V2G concept requires a power connection to the grid, a communication connection with the grid operator, and a suitable metering [23]. Furthermore, for a better balance of supply and demand, V2G scenario requires the interaction between the most important actors EV and SG. In this section we formally study this interaction by the use of a Bayesian game approach that represents 
one of the most important tools for modelling behaviours and strategies of interacting entities. We start by describing the proposed model that involves the major characteristics of EV (i.e. battery parameters, EV availability, the type of EV used) and the SG demand (i.e. the energy required to be supplied to the SG). We then provide the payoff matrix related to EV and SG. We finally predict the behaviour of EV and SG based on Bayesian Nash equilibrium.

\subsection{Game Model of EV and SG Interaction}

Bayesian game is an interactive decision involving several decision makers (i.e. players) in which the outcome of person's decision depends not only on how they choose among several options, but also on the choices made by the people they are interacting with [45]. In our approach, we consider two players representing the major actors in a V2G concept: SG and the EV. On one hand, the EV can perform two actions that are delivering electricity to the grid or not, this will depend on the price proposed by the grid in a given period of the day. On the other hand, the SG has also two actions which are charging from EV or not; knowing that the SG has to be charged permanently to satisfy the consumer's demand, so if it doesn't charge from EVs it will charge from the other fossils sources and this will affect its gain. The chosen action by a player affects the gain of the other player. EV and SG will choose the appropriate action in order to maximize their own gain. There will be a stable state at which no player cans increase its gain, this is achieved with a help of a Bayesian Nash Equilibrium; that we used to determine the future behaviors of both EV and SG.

Before presenting the utility matrix of the game between the SG and the $\mathrm{EV}$, we highlight and define in the following the notations and parameters used in our formulation by:

Battery degradation cost: Battery degradation is one of the chief challenges of V2G technology [46]. Due to natural limitations, the use of a battery is limited to a fixed number of cycles $\mathrm{L}_{\mathrm{C}}$. $\mathrm{L}_{\mathrm{C}}$ is thus the maximum number of cycles that the battery can charge/discharge in its life span [47]. Another parameter that deteriorates battery is the depth-of-discharge (DOD) [24, 25]. DOD is used to describe how deeply the battery is discharged (e.g. if a battery is $100 \%$ empty, the DOD of this battery is $100 \%$ ). Therefore, in order to extend the battery life time, the depth of discharge should not drop below certain level (e.g. PHEVs batteries are used up to $60 \%$ of DOD, while pure EVs are used up to $80 \%$ of DOD) [48]. The cost of battery degradation is given by the following relation [26]: 


$$
\mathrm{R}=\frac{\mathrm{C}_{\mathrm{bat}} / \mathrm{Cap}_{\mathrm{bat}}}{\mathrm{L}_{\mathrm{C}} * \mathrm{Cap}_{\mathrm{bat}} * \mathrm{DOD}}
$$

Where $\mathrm{C}_{\mathrm{bat}}$ represents the battery cost per $\mathrm{kWh}$ and Capbat is the capacity of the battery.

EV availability: In V2G technology, the availability of electric vehicles is necessary [49]. According to [50, 51], on one hand, more than $90 \%$ of all vehicles are parked at any given time and can be used for V2G supply. On the other hand, vehicle owners have an unpredictable nature and can move at any time. Thereby, in our approach we use a penalty constraint for the EV owner expressed as follows: if the level of the battery Bat level $(t)$ at time $t$ (i.e. the time when SG needs to charge) is greater than the needs of the driver and allows him to deliver energy to the SG and he does not do, he will be penalized. The needs of the driver is given by battery threshold $\mathrm{Bat}_{\mathrm{th}}(t)$, which is the minimum quantity of energy that must rest on battery for owner's travel. We want to point out that the penalty imposed to vehicle owner is not pecuniary (i.e. in this case EV will not lose money) but it is a kind of regret of not making money when the occasion was presented, this is well explained by the relation $\mathrm{X}_{21}$ below.

Quantity of delivered energy to the grid: this quantity is given by the following formula:

$$
\mathrm{QED}_{\mathrm{i}}(\mathrm{t})=\mathrm{DOD} *\left(\mathrm{Bat}_{\text {level }}(\mathrm{t})-\mathrm{Bat}_{\mathrm{th}}(\mathrm{t})\right)
$$

Quantity of required energy by the grid: The amount of requested energy by the grid at time $\mathrm{t}$ is related to its capacity level in this time $\mathrm{Cl}(\mathrm{t})$ and is given by:

$$
\mathrm{Q}_{\mathrm{eg}}(\mathrm{t})=\mathrm{Cap}_{\mathrm{eg}}-\mathrm{Cl}(\mathrm{t})
$$

Where $\mathrm{Cap}_{\mathrm{eg}}$ represents the grid capacity.

Environment benefit: As mentioned above, it is useless to electrify automobiles if the electricity that feeds their batteries is not produced from clean energy. Today $40 \%$ of $\mathrm{CO}_{2}$ emissions related to energy are caused by electricity production [52]. In 2013 as presented in Figure 1 [53], more than $67 \%$ of energies used to produce electricity was fossils (gas, petrol, carbon) which are the biggest emitter of greenhouse gases during their combustion; $11 \%$ was generated by nuclear, however nuclear is presented by its defendant as an ecological solution to protect our environment and even the solution in the fight against global warming climate because of their low $\mathrm{CO}_{2}$ emission but contrariety to these misconceptions we must know that the nuclear industry 


\section{World Electricity Production (TWh/year)}

Total 2013: 23,127 TWh. Source of data: BP

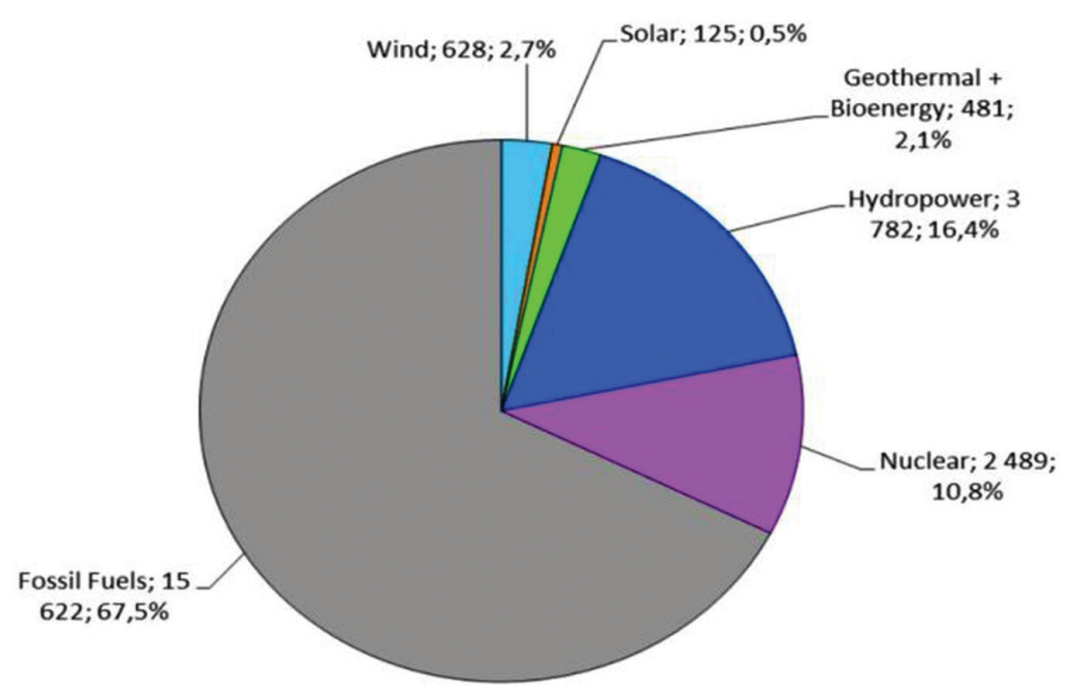

BCCONSULT

Figure 1 World electricity production in the year of 2013.

taken in its entirety rejects significant volumes of $\mathrm{CO}_{2}$ linked to the life cycle of the reactors, their fuel, and also to the need for fossil-fired plants during peak demand by Non-fossil fuels that emit no or little $\mathrm{CO}_{2}$ have occupied only $22 \%$ of the global electricity mix: $16 \%$ of world electricity was hydroelectric and 3\% was derived from the other green energy (solar, wind, geothermal, bioenergy) [52].

The minimal space occupied by the green sources for electricity production is due to the uncertainties of their availability that constraint increasingly the supply-demand balance of electrical system. This issue can be addressed by the development of renewable energy storage system. Furthermore, the storage of renewable energies permits recovering wasted energy in case of the excess on their production. There exist many technologies and means of green energy storage (Pumped Hydroelectric Storage, compressed air energy storage ... etc). However, for a small-scale storage, EVs play a promising role, first of all, the battery used in the storage is paid by EV owner and this will prevent the grid from equipment storage investment. Furthermore, EVs is decentralized load storage, this is another attractive point that will reduce 
need for costly electricity transmission systems. Add to this gain, the SG will avoid the social $\mathrm{CO}_{2}$ emission cost when charging green energy; this cost is used in our work as a penalty imposed to the grid if it refuses to charge from EV given by $P_{e}$. In the other case, it will charge from fossil energy and affect negatively the environment.

\subsection{Payoff Matrix}

In the following, we present the payoff matrix of the game between the SG and EV (see Table 1), where some notations are defined as follows:

Where: $p$ and $1-p$ are the probabilities with which the EV player performs that is deliver or do not deliver action, respectively, $\mathrm{q}$ and $1-\mathrm{q}$ are the probabilities with which the SG player performs that is charge or do not charge, respectively.

The payoff equation of each player is as follows:

$$
\begin{aligned}
& \mathrm{X}_{11}=-\sum_{\mathrm{i}=1}^{\mathrm{n}} \mathrm{QED}_{\mathrm{i}}(\mathrm{t}) * \mathrm{C}+\mathrm{V}(\mathrm{t}) * \sum_{\mathrm{i}=1}^{\mathrm{n}} \mathrm{Q}_{\mathrm{ED}}(\mathrm{t}) \cdot \mathrm{B}-\mathrm{n} * \mathrm{R} \\
& \mathrm{Y}_{11}=-\mathrm{V}(\mathrm{t}) * \sum_{\mathrm{i}=1}^{\mathrm{n}} \mathrm{Q}_{\mathrm{ED}_{\mathrm{i}}}(\mathrm{t}) \cdot \mathrm{B}+\mathrm{n} * \mathrm{P}_{\mathrm{e}} * \sum_{\mathrm{i}=1}^{\mathrm{n}} \mathrm{QED}_{\mathrm{i}}(\mathrm{t}) \\
& \mathrm{X}_{12}=-\sum_{\mathrm{j}=1}^{\mathrm{m}} \mathrm{Q}_{\mathrm{ED}_{\mathrm{j}}}(\mathrm{t}) \\
& \mathrm{Y}_{12}=\mathrm{P}_{\mathrm{e}} * \sum_{\mathrm{j}=1}^{\mathrm{m}} \mathrm{Q}_{\mathrm{egj}}(\mathrm{t}) \\
& \mathrm{Y}_{21}=\mathrm{Cl}(\mathrm{t}) \\
& \mathrm{X}_{22}=0
\end{aligned}
$$

Table 1 Payoff matrix between the two players: SG and EV

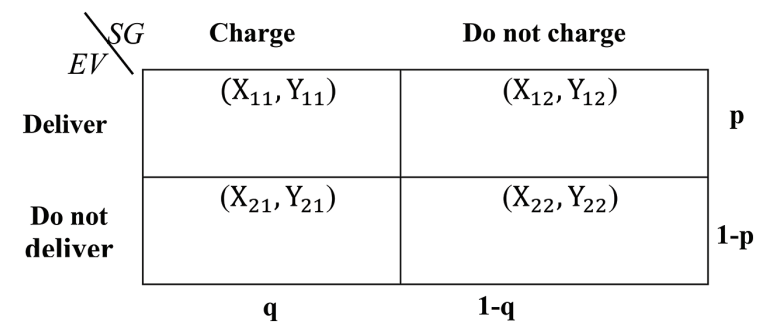


Interaction of Electric Vehicle and Smart Grid based on Game Theory 61

$$
\begin{gathered}
\mathrm{Y}_{22}=\mathrm{Cl}(\mathrm{t}) \\
\mathrm{X}_{21}=\left\{\begin{aligned}
-\sum_{\mathrm{j}^{\prime \prime}=1}^{\mathrm{k}}\left(\mathrm{Bat}_{\text {level }}(\mathrm{t})-\mathrm{Bat}_{\text {th }}(\mathrm{t})\right) * \mathrm{~V}(\mathrm{t}) * \mathrm{~B} \text { if } \mathrm{Bat}_{\text {th }}<\mathrm{Bat}_{\text {level }}(\mathrm{t}) \\
\text { if } \mathrm{Bat}_{\text {th }}>\mathrm{Bat}_{\text {level }}(\mathrm{t})
\end{aligned}\right.
\end{gathered}
$$

With:

- $\mathrm{C}$ is the electricity charging price by the EV. This cost is constant because we will take the cost of electricity unit in off-peak time, that is the most probable period of charging EV from renewable sources according to [40].

- $\mathrm{V}(\mathrm{t})$ price of electricity unit bought by $\mathrm{SG}$ at time $\mathrm{t}$. This price is related to time because we are using the Time of Use pricing (TOU) in valorising the cost of energy.

- B is a constant value that determines the period of the day when EV and SG are interacting.

$$
B=\left\{\begin{array}{l}
\mathrm{x}: \text { peak time if } t \in[7 \mathrm{PM}-9 \mathrm{PM}] \\
\mathrm{y}: \text { mid time if } t \in[7 \mathrm{AM}-1 \mathrm{PM}] \\
\mathrm{z}: \text { off peak time if } \mathrm{t} \in[3 \mathrm{AM}-6 \mathrm{AM}]
\end{array}\right.
$$

- $\mathrm{P}_{\mathrm{e}}$ is the penalty price imposed to the grid if it doesn't charge from EVs. This penalty is the cost of the emission of unit of carbon dioxide.

- $\mathrm{n}$ is the number of times that the vehicle delivers energy to the grid.

- $\mathrm{m}$ is the number of unsuccessful attempts to deliver energy to the grid. The EV delivers energy but the grid refuses to charge.

- $\mathrm{k}$ is the number of times that the vehicle rejects grid's demand. The SG wants to charge but the EV refuses to supply it.

- $\mathrm{i} \in\{1 \ldots \mathrm{n}\}, \mathrm{j} \in\{1 \ldots \mathrm{m}\}$, and $\mathrm{j} " \in\{1 \ldots \mathrm{k}\}$.

In the following, we describe the set of strategies that could occur between the SG and the EV.

\subsubsection{Strategy combination (Deliver \& Charge)}

In this case, the EV proposes to sell energy and the SG decides to charge. $\mathrm{X}_{11}$ represents the gain of $\mathrm{EV}$, which is the amount of energy delivered to the grid multiplied by the price of energy. On one hand, the price depends on the time operation. For instance, in a peak hour the gain of EV increases. On the other hand, the battery undergoes degradation when discharging [45], which will lead to decrease the EV's gain. The gain of SG, $\mathrm{Y}_{11}$, relies on the quantity 
of energy purchased from EV. In addition, the SG will economise the cost of $\mathrm{CO}_{2}$ emission given by $\mathrm{P}_{\mathrm{e}}$.

\subsubsection{Strategy combination (Deliver \& do not charge)}

In this strategy, the EV wants to sell the energy stocked in his battery to the SG, but this latter doesn't buy (i.e. does not charge). The grid refuses to charge because it has already the amount of energy needed or it had charged from another source and it does not need more energy. Here, $\mathrm{X}_{12}$ represents the failure of EV in selling energy to the grid, which is the amount of energy stored in its battery multiplied by the number of times that grid has refused to charge from EV. In this case, the grid will be penalized by the paying a cost for $\mathrm{CO}_{2}$ emission on the environment. This is represented by $\mathrm{Y}_{12}$.

\subsubsection{Strategy combination (Do not deliver \& Charge)}

In this case, the SG needs to charge, but the EV decides not to sell (i.e. do not deliver). The EV doesn't deliver because the energy remaining in his battery is sufficient only for his own usage (i.e. Battery level is lower than the level needed by the EV owner). If it is not the case (i.e. $\operatorname{Bat}_{\mathrm{th}}(t)<\operatorname{Bat}_{\text {level }}(t)$, the vehicle will be penalized. This penalty is represented by $\mathrm{X}_{21}$ and therefore, the SG keeps its capacity level as represented by $\mathrm{Y}_{21}$.

\subsubsection{Strategy combination (Do not deliver \& do not charge)}

In this case, the EV gain, $\mathrm{X}_{22}$, will be null since it does not deliver energy to the grid and the SG keeps its actual energy level as represented by $\mathrm{Y}_{22}$ value.

\subsection{Bayesian Nash Equilibrium}

The utility of Bayesian Nash Equilibrium (BNE) is to predict the future behaviour of the SG and the EV and determine the permanent state, i.e. each player has an interest in performing the same action [53]. Players are in equilibrium if they remain with the current strategy while the others remain invariant [50]. We use the BNE to determine the stage when both EV and SG do not change their actions, which are respectively delivering and charging.

\section{Theorem}

There is a mixed strategy $B N E\{E V$ player (deliver, p*), SG player (charge, $\left.\left.\mathrm{q}^{*}\right)\right\}$ in which the EV chooses the delivering action when the probability $\mathrm{p}<\mathrm{p}^{*}$ and the SG chooses the charging (i.e. permanent state action when $\mathrm{q}>\mathrm{q}^{*}$ ). 


\section{Proof}

On one hand, the EV expected payoff function UEV is defined as follows:

- $\operatorname{UEV}($ Deliver $)=\mathrm{q} \cdot \mathrm{X}_{11}+(1-\mathrm{q}) \cdot \mathrm{X}_{12}=\left[-\sum_{\mathrm{i}=1}^{\mathrm{n}} \mathrm{Q}_{\mathrm{ED}_{\mathrm{i}}}(\mathrm{t}) * \mathrm{c}+\mathrm{V}(\mathrm{t}) *\right.$ $\left.\sum_{\mathrm{i}=1}^{\mathrm{n}} \mathrm{Q}_{\mathrm{ED}}(\mathrm{t}) \cdot \mathrm{B}-\mathrm{n} * \mathrm{R}+\sum_{\mathrm{j}=1}^{\mathrm{m}} \mathrm{Q}_{\mathrm{ED}}(\mathrm{t})\right] \mathrm{q}-\sum_{\mathrm{j}=1}^{\mathrm{m}} \mathrm{Q}_{\mathrm{ED}}(\mathrm{t})$

- $\operatorname{UEV}($ Do not deliver $)=\mathrm{q} \cdot \mathrm{X}_{21}+(1-\mathrm{q}) \cdot \mathrm{X}_{22}=\left[-\sum_{\mathrm{j}=1}^{\mathrm{k}}\left(\operatorname{Bat}_{\text {level }}(\mathrm{t})-\right.\right.$ $\left.\left.\operatorname{Bat}_{\mathrm{th}}(\mathrm{t})\right) * \mathrm{~V}(\mathrm{t}) * \mathrm{~B}\right] \mathrm{q}$

The purpose of EV is to maximize its payoff by choosing for a fixed $\mathrm{p}^{*}, \mathrm{q}^{*}$ values that maximize the probability to deliver energy to the SG. This solution leads to equilibrium where the following equation should hold:

$$
\text { UEV (deliver) }\left(\mathrm{p}^{*}, \mathrm{q}^{*}\right)>\operatorname{UEV}\left(\text { Don't deliver) }\left(\mathrm{p}, \mathrm{q}^{*}\right)\right.
$$

The EV compute the optimal probability $\mathrm{q}^{*}$ by setting q equal to zero. This will result to the following equation:

$\mathrm{q}>\mathrm{q}^{*}$, where:

$$
\begin{aligned}
\mathrm{q}^{*}= & \frac{\sum_{\mathrm{j}=1}^{\mathrm{m}} \mathrm{Q}_{\mathrm{ED}_{\mathrm{j}}}(\mathrm{t})}{-\sum_{\mathrm{i}=1}^{\mathrm{n}} \mathrm{Q}_{\mathrm{ED}_{\mathrm{i}}}(\mathrm{t}) * \mathrm{c}+\sum_{\mathrm{j}=1}^{\mathrm{m}} \mathrm{Q}_{\mathrm{ED}_{\mathrm{i}}}(\mathrm{t})-\mathrm{n} * \mathrm{R}+\mathrm{V}(\mathrm{t}) * \mathrm{~B} *} \\
& \frac{\sum_{\mathrm{j}=1}^{\mathrm{m}} \mathrm{Q}_{\mathrm{ED}_{\mathrm{j}}}(\mathrm{t})}{\left[\sum_{\mathrm{i}=1}^{\mathrm{n}} \mathrm{Q}_{E D_{\mathrm{i}}}(\mathrm{t})+\sum_{\mathrm{j}^{\prime \prime}=1}^{\mathrm{k}}\left(\mathrm{Bat}_{\text {level }}(\mathrm{t})-\mathrm{Bat}_{\mathrm{th}}(\mathrm{t})\right)\right]}
\end{aligned}
$$

and $0<\mathrm{q}^{*} \leq 1$

On the other hand, the expected payoff function USG of the SG is defined as follows:

- $\operatorname{USG}($ Charge $)=\mathrm{p} \cdot \mathrm{Y}_{11}+(1-\mathrm{p}) \cdot \mathrm{Y}_{21}=\left[-\mathrm{V}(\mathrm{t})+\sum_{\mathrm{i}=1}^{\mathrm{n}} \mathrm{Q}_{\mathrm{ED}_{\mathrm{i}}}(\mathrm{t}) \cdot \mathrm{B}+\mathrm{n} *\right.$ $\left.\mathrm{P}_{\mathrm{E}} * \sum_{\mathrm{i}=1}^{\mathrm{n}} \mathrm{Q}_{\mathrm{ED}}(\mathrm{t})-\mathrm{Cl}(\mathrm{t})\right] \mathrm{p}+\mathrm{Cl}(\mathrm{t})$

- USG (Do not charge $)=$ p. $\mathrm{Y}_{12}+(1-\mathrm{p}) \cdot \mathrm{Y}_{22}=\left(+\mathrm{m} * \mathrm{P}_{\mathrm{e}} * \mathrm{Q}_{\mathrm{eg}}(\mathrm{t})+\right.$ $\mathrm{Cl}(\mathrm{t})) \mathrm{p}-\mathrm{Cl}(\mathrm{t})$

The purpose of SG is to maximize its payoff by choosing for a fixed $\mathrm{p}^{*}, \mathrm{q}^{*}$ values that maximize the probability to charge from EV, this solution leads to equilibrium where the following equation should hold:

$$
\text { USG (charge) }\left(p^{*}, q^{*}\right)>\operatorname{UEV}(\text { Don't charge })\left(p^{*}, q\right)
$$

The SG compute the optimal probability $\mathrm{p}^{*}$ by setting q equal to zero. This will result to: 
$\mathrm{p}<\mathrm{p}^{*}$ where

$\mathrm{p}^{*}=-\mathrm{V}(\mathrm{t}) \sum_{\mathrm{i}=1}^{\mathrm{n}} \mathrm{QED}_{\mathrm{i}}(\mathrm{t}) \cdot \mathrm{B}+\left(\mathrm{n} * \sum_{\mathrm{i}=1}^{\mathrm{n}} \mathrm{QED}_{\mathrm{i}}(\mathrm{t})-\mathrm{m} * \mathrm{Q}_{\mathrm{eg}}(\mathrm{t})\right) * \mathrm{P}_{\mathrm{E}}$

and $0<\mathrm{p}^{*} \leq 1$.

\section{Results and Discussions}

In this section, we evaluate the performance of the proposed V2G interaction game by simulation. The simulation is based on Matlab [29]. We use sample parameters and data from a real-life scenario. The daily grid demand energy data during the year of 2014 is obtained from California electricity grid in [54]. The electricity prices are 90.3 dollar per kilowatt-hour $(\$ / \mathrm{MWh})$ for green sources and from 67-130 \$/MWh for turbine gas, respectively, this price are given by time-of-use pricing in [55]. We set off-peak-time from 3:00AM to 6:00AM, the peak-time from 7:00PM to 9:00PM and the midtime from 7:00AM-6:00PM respectively. As we aim to the integration of renewable energies in SG within V2G. We perform our simulation on vehicle with Zero emission (i.e. $100 \%$ electric). The vehicle is a Nisan leaf with a typical lithium-ion battery model [56]. The battery parameters are given in Table 1, and its degradation cost is calculated by (1). The Nissan leaf battery cost is from 300 to 450 dollars per $\mathrm{kWh}$. We assume that the EVs were charged from renewable energies in off-peak-time with an average cost of 1.46 dollar per kWh. $20 \%$ of the fully charged battery is used by the owner for his travel, this represents the battery threshold. The quantity of energy delivered from the EVs to the SG grid is calculated by (2). The SG and EV will use this data to chose their actions; which are delivering or not and charging or not, for the EV and the SG respectively.

In the following, we provide simulation results to illustrate the properties of equilibrium strategies in the proposed game. We first analyse the interaction's

Table 2 Simulation parameters

\begin{tabular}{lll}
\hline Parameters & Definition & Value \\
\hline Cap & Battery capacity (kwh) & 24 \\
DOD & Depth of discharge & $80 \%$ \\
$\mathbf{L C}_{\mathbf{C}}$ & Life cycle & 1500 \\
$\mathbf{C}_{\text {bat }} /$ Cap $_{\text {bat }}$ & Battery cost (dollars/kWh) & $300-450$ \\
Bat $_{\text {th }}$ & Battery threshold & $20 \%$ \\
Capeg & Grid capacity (MWh) & 28000 \\
\hline
\end{tabular}


probability between SG and EV. Then, we evaluate the demand evolution, the price evolution and the impact of $\mathrm{V} 2 \mathrm{G}$ on environment.

\subsection{Probability Convergence}

It is shown in Figure 2(b) that the probability of delivering $\mathrm{q}^{*}$ is rising from the off-peak-time to the peak time from 0.41 to 0.84 . This result is achieved due to the two main parameters of EV's gain, which are, energy price and battery degradation cost. Furthermore, the energy cost at peak-time is more expensive than off peak-time, where the battery cost which is based on battery parameters remains the same during the three periods of the day. So, it is more profitable for the EV to sell its stocked energy at peak-times at a ceiling price. In Figure 1(a), the probability $p^{*}$ of charging by the smart grid during a peak-time is more important than off-peak-time. This increase is that the grid demand should cover all-time; otherwise the system will become unstable and may occur blackouts specifically in a peak-time. It is noted that, in a peak-time the requested energy reaches its maximum and consequently meets the high price of buying electricity. Despite this fact, the grid will choose the charging action to satisfy the lack in the energy needed. It can also be noted that the probabilities of charging and delivering (i.e. $\mathrm{p}^{*}$ and $\mathrm{q}^{*}$ ) depend on the number of EVs since when this later increases both probabilities increase. From these analyses, we conclude that $\mathrm{V} 2 \mathrm{G}$ could be beneficial for EV and SG when they choose respectively delivering and charging actions at peak-time.

\subsection{Demand Evolution}

Figure 3 shows a demand evolution of grid in function of the number EVs. According to the energy delivered per vehicle in the three periods of the day (off-peak-time, mid-time and peak-time). We can see that there is an inverse correlation between the number of EVs and the amount of energy delivered per EV, as the quantity of total energy supplied to the grid becomes sizable when the number of EV is increasing. At first, the grid needs a big amount of energy and after a moment, its level will be filled up and therefore the amount of energy needed by the grid decreases and also the number of EVs.

\subsection{Price Evolution}

Figure 4 represents a comparison of purchasing electricity price from green sources and non-green sources. On one hand, we found out that the prices are increasing from off-peak-time to peak-time for both sources. On the other 

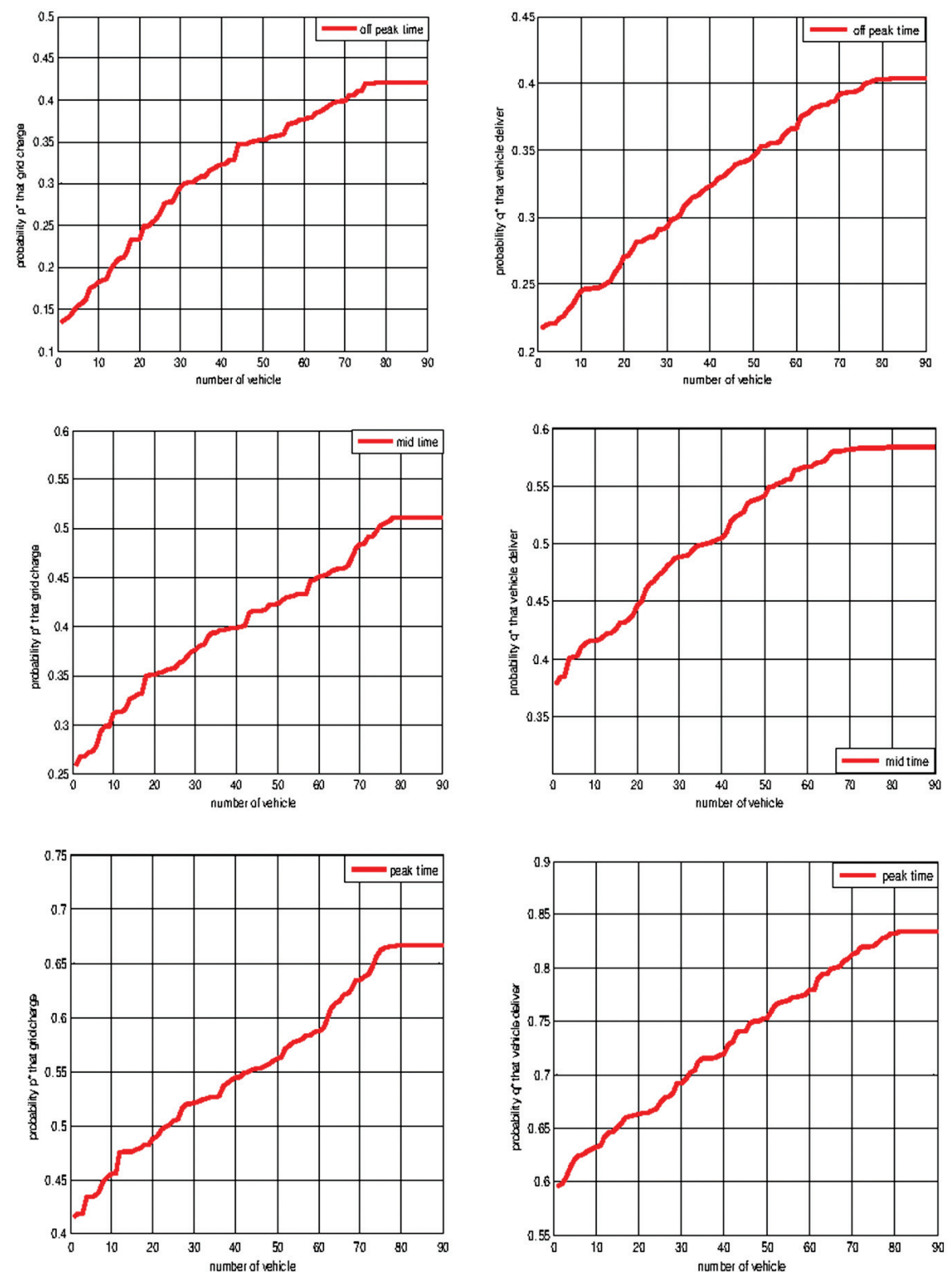

(a)

(b)

Figure 2 Probability convergence: (a) Probability p* that the grid charges, (b) Probability $\mathrm{q}^{*}$ that the electric vehicle delivers. 


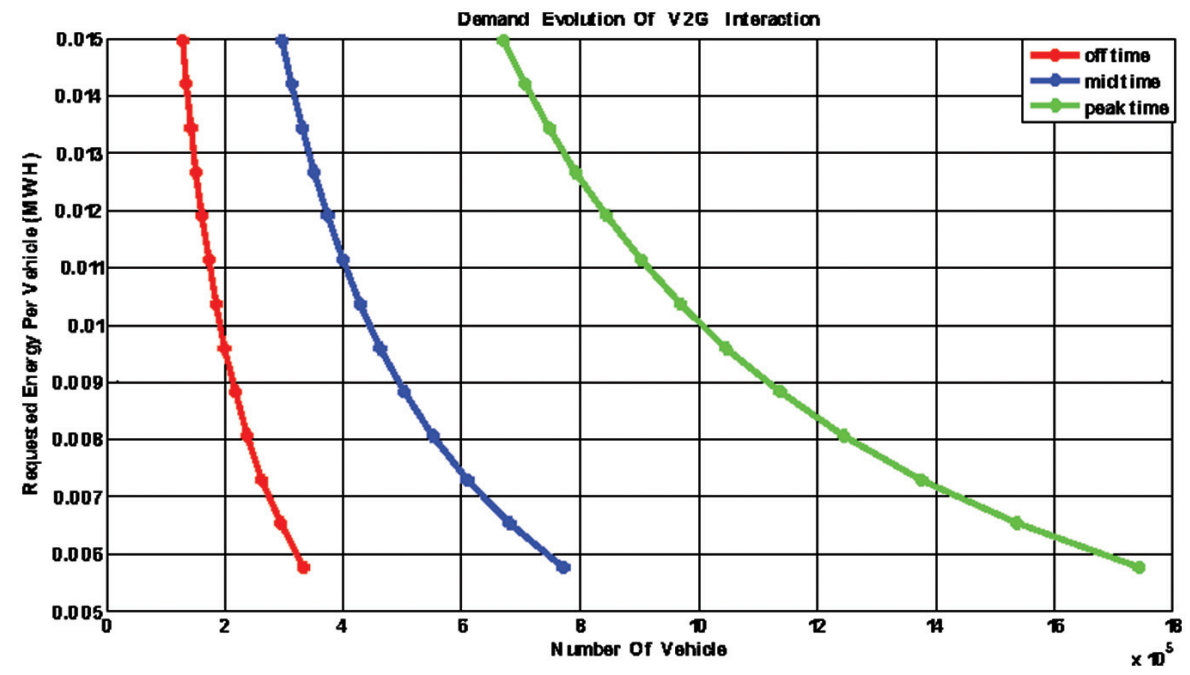

Figure 3 Demand evolution.

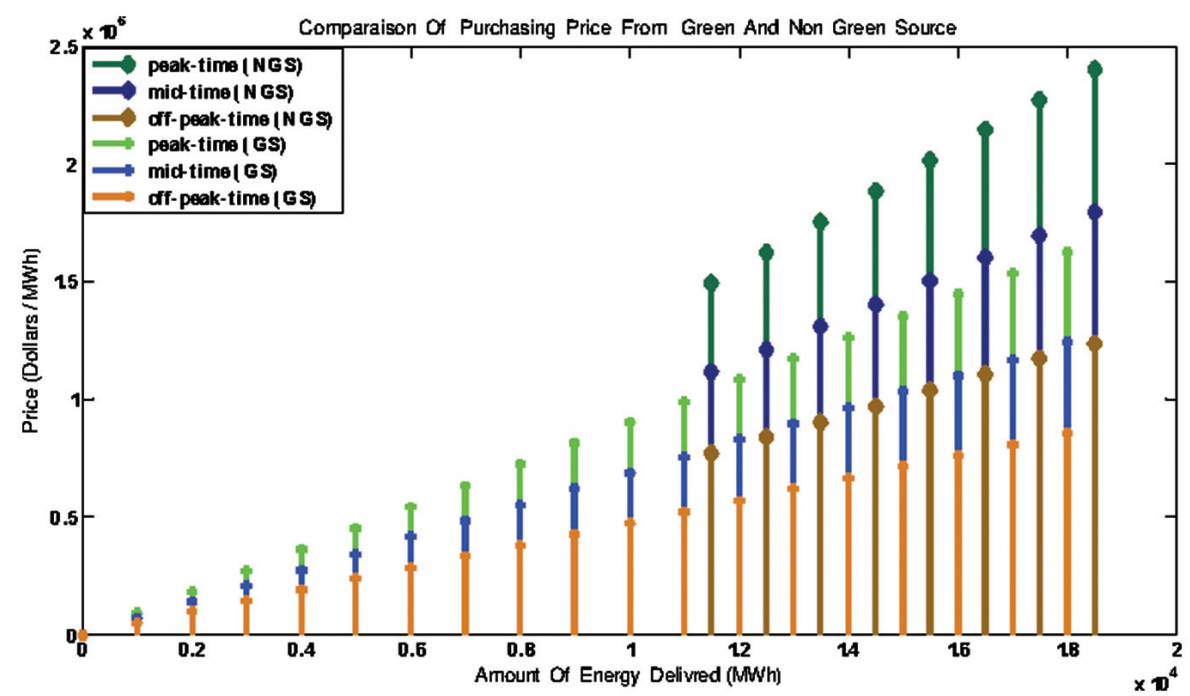

Figure 4 Price evolution.

hand, we show that a high cost of purchasing price of non-green sources about $0.3 \%$ compared with green sources. Furthermore, when the amount of energy delivered is inferior to $1.3 * 10^{5} \mathrm{MWh}$, the purchasing price of 
non-green sources is null. This is due to the fact that when grid decides to charge, it prefers charging only from green sources; which are more profitable for grid economy and more beneficial for environment (see impact of V2G on environment below). Moreover, if the level of grid is not yet filled, it will be obliged to recur to complete its charge from non-green sources and that is illustrated in our study.

Besides the lower price of green sources, in V2G, EVs will be actors in the promotion of renewable energy without engaging large investments (e.g. EVs are dynamic; the SG will pay only the energy bought without investing in electrical distribution line).

\subsection{Impact of V2G on Environment}

The following Table 3 [57] represents the electricity system power in California. The biggest source used for electricity generation is natural gas with 330 to $360 \mathrm{~g} \mathrm{CO}_{2}$ emission per $\mathrm{kWh}$ [58]. The natural gas represents $61.3 \%$ of California In-State Generation and 45, 5\% of the total mix power. On the other hand, the renewable energies those represent a negligible $\mathrm{CO}_{2}$ emission compared with natural gas, where an average of only $25 \mathrm{~g} \mathrm{CO}_{2}$ is emitted for electricity production by renewable energies, takes $20.1 \%$ of the total mix power. At it is shown in the table, to compensate it total electricity needs, the California state recourses to importation. More than $45 \%$ of its total energy importation is fossils (coal and gas) and 13\% is nuclear, this policy is the main causes of environmental damage and here appears the impact of $V 2 G$ for the integration of the renewable energies in the power system in order to reduce the negative impact of fossil electricity on the environment.

In 2013 California have adopted 174.000 EVs. Those EVs include 70.000 with zero emission [59]. If those EVs inject back power to the grid within the V2G interaction game with an average of only $1 \mathrm{kWh}$ per EV per day 25, 55 Gigawatt-heure [GWh] of renewable energy will be added to the mix of power. This is approximately the quantity of (coal + nuclear) imported, this will avoid the emission of millions of ton of $\mathrm{CO}_{2}$ caused by electricity generation.

The proposed game approves this environmental benefit, where EVs charge in the best ecological and economic conditions, storing and absorbing a part of the production "fatal" of renewable energy and reinjecting energy on the grid during peak demand, thus avoiding to start coal-fired or gas very expensive and emitting $\mathrm{CO}_{2}$. 


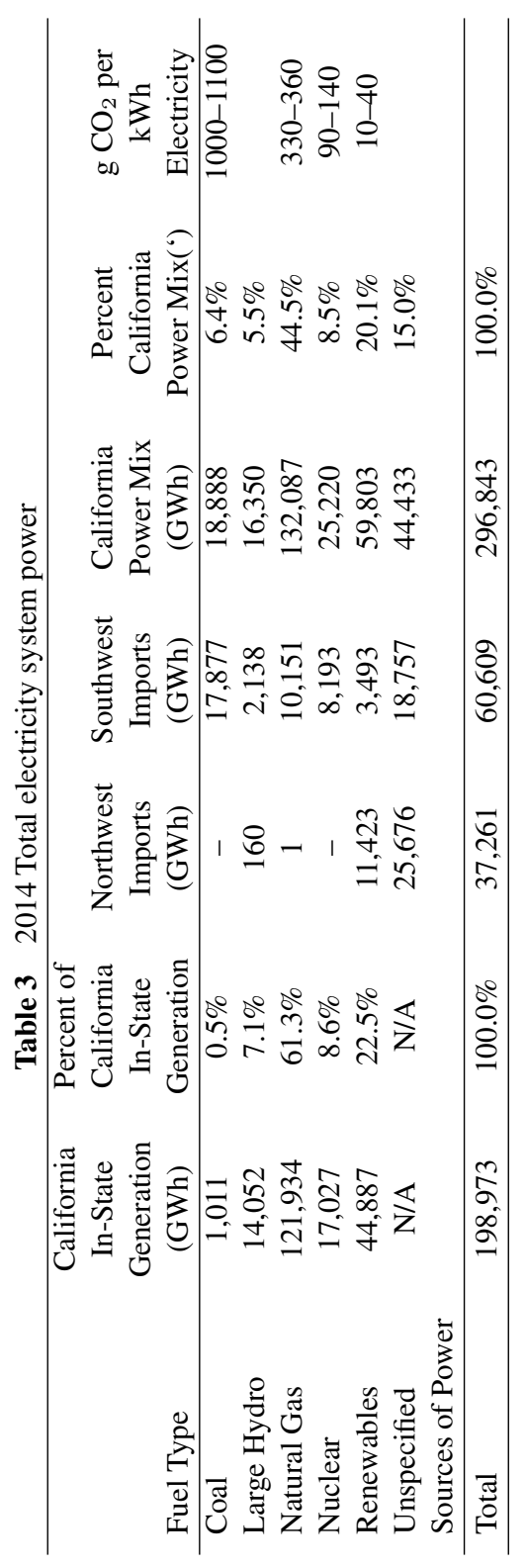




\section{Conclusion}

For a green environment, certainly, the efforts should be directed towards the electrification of transportation. However, how to produce energy is just as important. This work focuses on the interaction between EV and SG in V2G technology with objective of integrating renewable sources (green sources) in SG. To study this interaction, a Bayesian game is formulated first. Then, based on a Bayesian Nash Equilibrium (BNE), we evaluate interaction's probability between SG and EV for the three periods of the day (off-peak, mid and peak hours). Results show that the EV will choose peak-time as the more profitable moment of the day for delivering electricity to SG. As well, peak-time is also chosen by the grid to be the best moment for charging action. These results confirm that the proposed model yields are acceptable as they adhere to the global concept of V2G (i.e. charging EV at off-peak-time and discharging to the SG at peak time). Furthermore, to study the income of the integration of renewable sources in SG, a comparison between green sources and nongreen sources that evaluate the cost and the impact on environment has been performed. Green sources show a great advantage compared to the non-green sources in term of cost. Moreover, the emission of $\mathrm{CO}_{2}$ of green sources is almost non-existent compared with non-green sources. Even if SG chooses to charge from green sources for their low cost and environment profit, at peak time SG is obliged to combine these sources with non-green sources to provide a continuous electrical production (that is without interruption). Throughout this paper, we have assumed a series of interaction between EV and SG, where we consider different parameters and characteristics such as the battery's capacity, the battery lifetime, EV availability, the SG capacity, the environment benefit. The target market chosen for our study is peak load, where the major objective of the proposed model is encouraging the integration of renewable sources in SG.

As perspective, we aim to extend the proposed model to study the interaction between EV and SG for the other markets (spanning reserve and frequency regulation) and propose a game mode between a group of EVs and SG.

\section{References}

[1] D. Said, S. Cherkaoui and L. Khoukhi, "Scheduling Protocol with Load Management for EV Charging," IEEE GlobalCommunications Conference (GlobCom), Austin, Texas USA, pp.8-12, Dec. 2014. 
[2] Tridib K Biswas and N Biswas, "Electic Vehicle: A Natural Option For India ?", IETE Technical Review Vol. 16, Issue 3-4, March 2015.

[3] S. Bahramiand M. Parniani, "Game theoretic based charging strategy for plug-in hybrid electric vehicles," IEEE Trans. Smart Grid, vol.5, pp.2368-2375, sept. 2014.

[4] A. Saber and G. Venayagamoorthy, "Plug-in vehicles and renewable energy sources for cost and emission reductions," IEEE Trans Industrial Electronics, vol.58, pp. 1229-1238, Mars.2011.

[5] Y. Lim, J. Park, H-M Kim and T. Kinoshita, "A Bargaining approach to optimizing load shedding in islanded microgrid operation ", IETE Technical Review, Vol. 30, pp.483-489, Nov 2013.

[6] S. L. Andersson, A. K. Elofsson, M. D. Galus, L. Göransson, S. Karlsson, F. Johnsson and G. Andersson, "Plug-in hybrid electric vehicles as regulating power providers: Case studies of Sweden and Germany," Energy policy, vol. 38, no.6, p. 2751-2762. June 2010.

[7] T. Morgan, "Smart grids and electric vehicles: Made for each other?". International Transport Forum. United Kingdom, Menecon Consulting, April 2012.

[8] Y. Yao, "The WoT framework for the vehicle-to-grid (V2G) implementation", IEEE Conf. Transportation Electrification Asia-Pacific (ITEC Asia-Pacific), pp.1-4, Sept. 2014.

[9] H. Liang, B. Choi, W. Zhuang and X. Shen, "Optimizing the energy delivery via V2G systems based on stochastic inventory theory," IEEE Trans. Smart Grid, vol. 4, no. 4, pp. 2230-2243, Dec. 2013.

[10] C. Liu, K. Chau, D. Wu and S. Gao. "Opportunities and challenges of vehicle-to-home, vehicle-to-vehicle, and vehicle-to-grid technologies", IEEE Proceeding, vol.101, pp. 2409-2427, Oct. 2013.

[11] W. Shireen, S. Patel, "Plug-in Hybrid Electric Vehicles in the Smart Grid Environment," IEEE conf. Transportation andDistribution, pp.1-4, April 2010.

[12] M. Kintner, K. P. Schneider and R. G. Pratt, "Impacts Assessment of Plug-in Hybrid Vehicles on Electric Utilities and Regional US Power Grids Part 1: Technical Analysis Pacific Northwest National Laboratory," IEEE International Symposium on Sustainable Systems and Technology (ISSST), pp.1-6, May 2012.

[13] M. Ansari, A. Al-Awami, E. Sortomme, and M. Abido "Coordinated Bidding of Ancillary Services for Vehicle-to-Grid Using Fuzzy Optimization," IEEE Trans. Smart Grid, no. 1, vol.6, pp. 261-270, Dec 2014. 
[14] Lund H. "Large-scale integration of wind power into different energy systems". Energy- Elsevier, vol. 30, pp. 2402-2412, Oct 2005.

[15] Blewitt G, Coolbaugh M, Holt W, Kreemer C, Davis J, Bennett R. "Targeting potential geothermal resources in the Great Basin from regionalto basin- scale relationships between geodetic strain and geological structures". Geo- thermal Resources Council Transactions, vol.27, pp. 3-7, 2003.

[16] A. Y. Saber and G. K. Venayagamoorthy, "Plug-in vehicles and renewable energy sources for cost and emission reductions," IEEE Trans. Indust. Electron., vol. 58, no. 4, pp. 1229-1238, Apr. 2011.

[17] B. V. Mathiesen, H. Lund, D. Connolly, H. Wenzel, P. stergaard, B. Moller, S. Nielsen, I. Ridjan, P. Karne, K. Sperling, et al, "Smart Energy Systems for coherent $100 \%$ renewable energy and transport solutions", Applied Energy-Elsevier, vol.145, pp.139-154, May.2015.

[18] D. Larcher, J-M. Tarascon "Towards greener and more sustainable batteries for electrical energy storage", Nature Chemistry, pp. 17-29, 2015.

[19] A. Zahedi, "Maximizing solar PV energy penetration using energy storage technology", Renewable and Sustainable Energy Reviews, vol.15, pp.866-870, 2011.

[20] W. Kempton, S. Letendre, "Electric vehicles as a new power source for electric utilities", Transportation Research Part D: Transport and Environment, no 3, vol. 2, pp. 157-175, 1997.

[21] W. Kempton, J. Tomic, S. Letendre, A. Brooks, and T. Lipman. "Vehicleto-grid power: Battery, hybrid, and fuel cell vehicles as resources for distributed electric power in California. Prepared for California Air Resources Board and the California Environmental Protection Agency, 2001.

[22] A. Damiano, G. Gatto, I. Marongiu, M. Porru, and A. Serpi, "Vehicle togrid technology: State-of-the-art and future scenarios," Journal of Energy and Power Engineering, vol. 8, no. 1, pp. 152-165, Jan. 2014.

[23] A. N. Brooks, "Vehicle-to-Grid Demonstration Project: Grid Regulation Ancillary Service With a Battery Electric Vehicle". Final Report Prepared for the California Air Resources Board and the California Environmental Protection Agency, December 2002.

[24] W. Kempton, V. Udo, K. Huber, K. Komara, S. Letendre, S. Baker, D. Brunner, and N. Pearre. "A test of vehicle-to-grid (V2G) for energy storage and frequency regulation in the PJM system," Mid-Atlantic Grid Interactive Cars Consortium, 2009. 
[25] J. Lassila, J. Haakana, V. Tikka, and J. Partanen, "Methodology to analyze the economic effects of electric cars as energy storages," IEEE Trans. Smart Grid, no. 1, vol. 3, pp. 506-516, Mar. 2012.

[26] W. Kempton, J. Tomi c, "Vehicle-to-grid power fundamentals: calculating capacity and net revenue", J. Power Sources, pp.268-279, 2005.

[27] S. Mehar, S. Zeadally, S. M. Senouci, and G. Remy, "Sustainable Transportation Management System for a Fleet of Electric Vehicles (STMS)," Accepted in IEEE Transactions on Intelligent Transportation Systems.

[28] B. Dunn, H. Kamath, J. M Tarascon, "Electrical Energy Storage for the Grid: A Battery of Choices", J. Science, vol.334, pp.928-925, Nov. 2011.

[29] M. Yilmaz, P. T Krein, "Review of benefits and challenges of vehicle-togrid technology", IEEE. Energy Conversion Congress and Exposition (ECCE), pp. 3082-3089, 2012.

[30] J. Tomic and W. Kempton, "Using fleets of electric-drive vehicles for grid support," J. Power Sources, no. 2, vol. 168, pp.459-468, 2007.

[31] A. De Los Rios, J. Goentzel, K. E. Nordstrom, and C. W. Siegert, "Economic Analysis of Vehicle-to-Grid (V2G)-Enabled Fleets Participating in the Regulation Service Market," IEEE PES Innovative Smart Grid Tech. Conf. (ISGT), January 2012.

[32] D. Dallinger, D. Krampe, and M. Wietschel, "Vehicle-to-grid regulation reserves based on a dynamic simulation of mobility behavior," IEEE Trans. Smart Grid, no. 2, vol. 2, pp. 302-313, 2011.

[33] S. Hanand, K. Sezaki, “ Development of an optimal vehicle-to-grid aggregator for frequency regulation," IEEE Trans. Smart Grid, no.1, vol. 1, pp. 65-72, 2010.

[34] E. Sortomme, MA. El-Sharkawi, " Optimal charging strategies for unidirectional vehicle-to-grid”. IEEE Trans. Smart Grid, pp:1-8, 2011.

[35] R. Faria, P. Moura, J. Delgado, and A. de Almeida. "Managing the charging of electrical vehicles: impacts on the electrical grid and on the environment." IEEE Intelligent Transportation Systems Magazine, vol. 6: pp:54-65, 2014.

[36] M. Wang, H. Liang, R. Zhang, R. Deng, and X. Shen, "Mobility-aware coordinated charging for electric vehicles in VANET-enhanced smart grid," IEEE J. Sel. Areas Commun., vol. 32, no. 7, pp. 1344-1360, Jul. 2014.

[37] J. Lassila, V. Tikka, J. Haakana, and J. Partanen, "Electric cars as part of electricity distribution-Who pays, who benefits?" IET Elect.Syst.Transp, no. 4, vol. 2, pp. 186-194, Dec. 2012. 
[38] E. Veldman, R. A. Verzijlbergh, "Distribution Grid Impacts of Smart Electric Vehicle Charging From Different Perspectives", IEEE Trans. Smart Grid, no.1, vol.6, pp.333-342, 2014.

[39] K. Mets, R. D'hulst, and C. Develder, "Comparison of intelligent charging algorithms for electric vehicles to reduce peak load and demand variability in a distribution grid," J. Commun. Netw, no. 6, vol. 14, pp. 672-681, Dec. 2012.

[40] M. Attia, H. Sedjlmaci, SM. Senouci and E. Aglzim "Theoretic-Game Model to Optimally Combine Electric Vehicles with Green and NonGreen Sources into an End-to End Smart Grid Architecture", under submission.

[41] S. B. Peterson, J. F. Whitacre, and J. Apt, "The economics of using plug-in hybrid electric vehicle battery packs for grid storage," J. Power Sources, no. 8, vol. 195, pp. 2377-2384, Apr. 2010.

[42] R. Yu, J Ding, W Zhong, Y Liu, and S Xie."PHEV Charging and Discharging Cooperation in V2G Networks: A Coalition Game Approach," J. Internet of Things, Vol.1, no. 6, pp.578-589, oct. 2014.

[43] R.Thirugnanam, K. Kumar, P. Lavudiya, and R. Singh, M. "Mathematical Modeling for Economic Evaluation of Electric Vehicle to Smart Grid Interaction," IEEE Trans. Smart Grid, no.2, vol.5, pp.712-721, March 2014.

[44] J. Tan and L. Wang, "Integration of plug-in hybrid electric vehicles into residential distribution grid based on two-layer intelligent optimization," IEEE Trans. Smart Grid, no. 4, vol. 5, pp. 1774-1784, Jul. 2014.

[45] D. Easley, J Kleinberg Networks, Crowds, and Markets: Reasoning About a Highly Connected World, Cambridge University Press, 2010[online] Available: http://www.cs.cornell.edu/home/kleinber/ networks-book/

[46] C. Zhou, K. Qian, and W. Zhou, "Modeling of the cost of EV battery wear due to V2G application in power systems," IEEE Trans. Energy Convers, no. 4, vol. 26, pp. 1041-1050, Dec. 2011.

[47] Xin. Wang, Qilian. Liang, "Energy Management for Plug-in Hybrid Electric Vehicles via Vehicle-to-Grid", IEEE International Conference on Communications (ICC), pp. 4197-4201. 2013.

[48] F. Marra, C. Træholt, E. Larsen and Q. Wu, "Average Behavior of Battery Electric Vehicles for Distributed Energy Studies”, IEEE Conf, Innovative Smart Grid Technology, pp.1-7. Oct. 2010.

[49] K. M. Zhang, and C. D. White, "Using Vehicle-to-Grid Technology for Frequency Regulation and Peak-load Reduction," J. Power Sources, Vol.196, pp. 3972-3980. 2011. 
[50] E. Negeri, and N. Baken, "Smart Integration of Electric Vehicles in an Energy Community," In Proc. of the 1st Int. Conf. on Smart Grids and Green IT Systems, pp. 25-32, Apr. 2012.

[51] M. Hatfield. "Game Theory in Management: Modelling Business Decisions and Their Consequences", Gower Publishing, Ltd., 2012.

[52] EIA report, Emissions of Greenhouse Gases in the United States 2009, [Online] Available: http://www.eia.gov/environment/emissions/ghg_re port/ghg_overview.cfm

[53] dd. Magazine [online] Available: http://www.ddmagazine.com/2859La-production-electrique-mondiale-en-chiffres.html

[54] J. Farrell, "Utilities Cry "Fowl" Over Duck Chart And Distributed Solar Power" in clean technica, [on line]. Avalable:http://cleantechnica.com, utilities-cry-fowl-over-duck-chart-and-distributed solar-powercryingfowl-or-crying-wolf-open-season-on-the-utilitys-solar-duck-chart2014

[55] H. McCook, "Under the Microscope: The True Costs of Gold Production" in Coin-Desk. [online]. Available: http://www.coindesk.com/micro scope-true-costs-gold-production/, 2014.

[56] Automobile Propre, [online]. Available: http://www.automobile-propre. com/voitures/nissan-leaf/\#Batterie_Autonomie_de_la_Nissan_LEAF

[57] California Energy Commission, [online]. Available: http://energyal manac.ca.gov/electricity/total_system_power.html

[58] Time of change, [online]. Available: http://timeforchange.org/co2emission-nuclear-power-stations-electricity

[59] U.S Energy Information Administration, [online]. Available: https://www. eia.gov/todayinenergy/detail.cfm?id=19131 
